\title{
Early history of glycine receptor biology in mammalian spinal cord circuits
}

\section{Robert John Callister* and Brett Anthony Graham}

School of Biomedical Sciences and Pharmacy, The University of Newcastle and Hunter Medical Research Institute, Newcastle, NSW, Australia

\section{Edited by:}

Robert J. Harvey,

University of London, UK

Reviewed by:

Peter A. Smith,

University of Alberta, Canada

Robert M. Brownstone, Dalhousie

University, Canada

*Correspondence:

Robert John Callister,

School of Biomedical Sciences and

Pharmacy, The University of

Newcastle, Callaghan, Newcastle, NSW 2308, Australia.

e-mail: robert.callister@newcastle. edu.au
In this review we provide an overview of key in vivo experiments undertaken in the cat spinal cord in the 1950s and 1960s, and point out their contributions to our present understanding of glycine receptor (GlyR) function. Importantly, some of these discoveries were made well before an inhibitory receptor, or its agonist, was identified. These contributions include the universal acceptance of a chemical mode of synaptic transmission; that GlyRs are chloride channels; are involved in reciprocal and recurrent spinal inhibition; are selectively blocked by strychnine; and can be distinguished from the GABA $A_{A}$ receptor by their insensitivity to bicuculline. The early in vivo work on inhibitory mechanisms in spinal neurons also contributed to several enduring principles on synaptic function, such as the time associated with synaptic delay, the extension of Dale's hypothesis (regarding the chemical unity of nerve cells and their terminals) to neurons within the central nervous system, and the importance of inhibition for synaptic integration in motor and sensory circuits. We hope the work presented here will encourage those interested in GlyR biology and inhibitory mechanisms to seek out and read some of the "classic" articles that document the above discoveries.

Keywords: chloride channel, motoneuron, Renshaw cell, strychnine, bicuculline, inhibition, synaptic transmission

\section{INTRODUCTION: A BRIEF HISTORY OF GIYR STUDY}

This review is directed at graduate students whose research focuses primarily on the genetic and molecular aspects of glycine receptor (GlyR) function, and the experienced researcher with an interest in the pivotal experiments that established the fundamentals of GlyR biology and inhibitory synaptic transmission. We use two well-understood motor circuits, located in the spinal cord, to illustrate how our current understanding of GlyR function evolved (Figure 1). Where possible, we refer to the crucial involvement of GlyRs in reflexes and motor behaviors because strychnine, the selective antagonist of the GlyR, has long been used to reveal mechanisms underlying motor behaviors such as locomotion. For example, at the behavioral level, strychnine administration in spinalized animals greatly facilitates reflex walking. This observation indicates ongoing (or tonic) supra-segmental inhibition is vital for normal locomotor co-ordination (Hart, 1971). Likewise, strychnine administration disturbs the normal modulation of motoneuron discharge during fictive locomotion (Pratt and Jordan, 1987). These data are consistent with inhibition being important for modulating activity in muscle groups that underlie rhythmic motor behaviors.

GlyR biology is currently undergoing a "mini" renaissance because a new form of the receptor (containing $\alpha 3$ subunits) was recently identified in sensory divisions of the spinal cord, specifically those involved in pain processing (Harvey et al., 2004). This basic science finding is now driving work aimed at identifying ways to selectively modulate the $\alpha 3$-form of the receptor and improved pain therapies (Zeilhofer, 2005; Lynch and Callister, 2006). We therefore feel it is timely to review some of the in vivo history of GlyR biology, which began in the cat spinal cord, and outline how current views of this receptor and its function evolved from the initial quest to understand motor control pathways and synaptic transmission in the mammalian central nervous system (CNS).

We consider the first important period for GlyR biology, and the focus of this review, to have occurred during the 1950-1960s when fundamental aspects of inhibitory synaptic transmission were being revealed by application of extracellular and intracellular recording techniques to neurons in the cat spinal cord. Early in this period, the GlyR and its endogenous agonist were yet to be identified. The next phase of GlyR research, during the 1970s - 1990s, was very much concerned with in vitro experimentation. This involved work on recombinant GlyRs, where the receptor was considered a "proto-typical" ligand gated ion channel, or experiments on acute spinal cord and brainstem preparations that examined the pharmacolology and physiology of native GlyRs. Considerable advantages were provided by the apparent expression of only one type of GlyR (comprised of $\alpha 1$ and $\beta$ subunits) in the adult nervous system for structure-function studies on recombinant channels, especially compared to its close relative, the $\gamma$-amino-n-butyric acid receptor $\left(\mathrm{GABA}_{\mathrm{A}} \mathrm{R}\right)$, where multiple subtypes existed (Mody and Pearce, 2004; Sarto-Jackson and Sieghart, 2008). Work over this period has been summarized in previous reviews (Legendre, 2001; Lynch, 2004). At this time, translation of findings to the clinic was hampered by the widespread distribution of a single form of the receptor in the mammalian CNS, as well as the toxicity of its major antagonist strychnine.

These disadvantages for clinical applications were balanced by the discovery and study of naturally-occurring mutations in the GlyR in a number of species including humans, horses, dogs and mice (Floeter and Hallett, 1993; Rajendra and Schofield, 1995). 


\section{A \\ Feline spinal preparation}

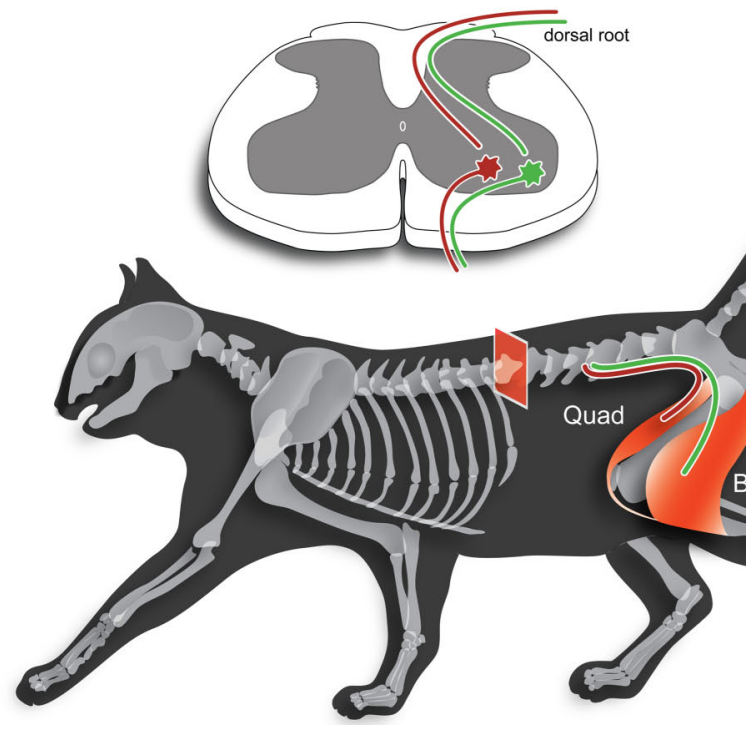

B Reciprocal pathway

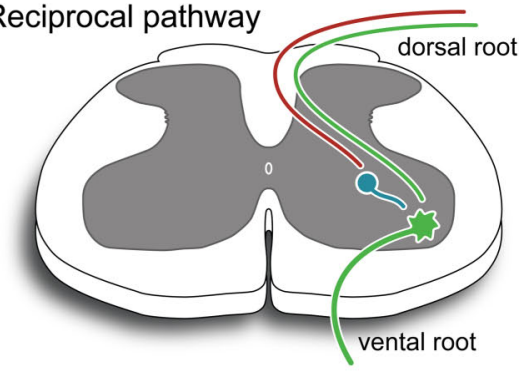

C Recurrent pathway

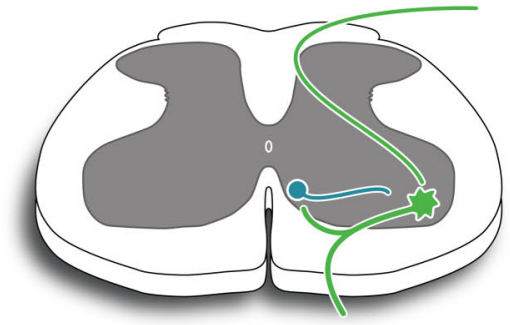

FIGURE 1 | Key spinal cord motor pathways used to study synaptic mechanisms in the mammalian CNS. (A) Schematic illustrating two hind limb muscles employed extensively in the study of spinal cord reflexes and synaptic transmission in the 1950s and 1960s. The quadriceps (Quad) and bicepssemitendonosus (BCST) muscles produce extension and flexion about the knee joint, respectively. Inset, shows a spinal cord cross-section and the monosynaptic excitatory pathway. Afferents originating in annul spiral endings of muscle spindles (1a afferents) are involved in the classic stretch reflex, which is used clinically to test the integrity of spinal circuits. These afferents (red and green axons) make monosynaptic connections with motoneurons that innervate the same (homonymous) muscle. (B) Inhibition is produced in motoneurons by activation of 1a afferents in antagonist muscles. In early work, this pathway was called the "direct inhibitory pathway" because stimulation of an antagonist muscle nerve (e.g., Quad) could directly inhibit responses in motoneurons innervating BCST. This inhibition is provided by an interposed 1a inhibitory interneuron (shown in blue). This pathway is now termed the "reciprocal inhibitory pathway" to better reflect its peripheral action where it ensures antagonist muscles are relaxed when agonist muscles are activated during movement. (C) Inhibition can also be produced in motoneurons by antidromic stimulation of agonist muscle nerves or ventral roots. This inhibition is provided via another type of inhibitory interneuron, termed a Renshaw cell (shown in blue), which is activated by motoneuron axon collaterals. This pathway is called the "recurrent inhibitory pathway".
Importantly, humans and animals with GlyR mutations exhibited markedly similar motor phenotypes that collectively have been termed "startle diseases". The animal models provided insight into diseases involving tremor and spasticity, and how they might be treated (Simon, 1995). The existence of naturally-occurring murine mutants provided new research directions, because GlyRs could now be examined both genetically and behaviorally within a single species. Work on native GlyRs in brainstem and spinal motor neurons in murine mutants provided insights, at the level of intact synapses, into mechanisms underlying the exaggerated motor responses observed in humans and animals with GlyR defects (Biscoe and Duchen, 1986; von Wegerer et al., 2003; Graham et al., 2006). Additionally, GlyR levels and subunit composition could be manipulated in mice and then studied at the channel, synapse, and behavioral levels of analysis (Hartenstein et al., 1996; Becker et al., 2000). Recent work has also allowed in vivo electrophysiological analysis of neuron excitability and spinal cord circuits in deeply anesthetized mice with GlyR mutations (Graham et al., 2007a).

The past decade has seen an increased focus on GlyR function in regions of the nervous system that process sensory information. Interestingly, these experiments have been conducted in sensory regions of the spinal cord where GlyR mutations don't appear to have the catastrophic effects observed in the motor system. Recent work on dorsal horn neurons suggested inhibitory tone is maintained, at least in some GlyR mutants, by compensatory changes in $\mathrm{GABA}_{\mathrm{A}} \mathrm{R}$ expression and altered potassium channel function on postsynaptic neurons (Graham et al., 2003, 2007b). These findings are important for our understanding of the co-regulation of the two major fast inhibitory channels and the mechanisms by which excitability is regulated in neuronal circuits. Importantly, such insights are only available after re-examination of in vitro findings in intact (in vivo) preparations using electrophysiological and behavioral analysis. Such inquiry is now entirely feasible so that discoveries made using genetic/molecular techniques can be re-examined at both the circuit and systems levels of investigation.

\section{UNDERSTANDING AND DEFINING CENTRAL INHIBITORY MECHANISMS: DISCOVERIES MADE IN THE CAT SPINAL CORD}

It is now well accepted that two classic reflex pathways exist within the CNS, which play an important role in fast synaptic inhibition on motoneurons in spinal cord circuits. The circuitry and principle neuron types involved in these pathways are highlighted in Figure 1. Such circuit diagrams are often presented as the "first slide" in seminars or talks to emphasize the importance of GlyRs and inhibitory neurotransmission in CNS function. We now take for granted how GlyRs, along with closely related $\mathrm{GABA}_{\mathrm{A}} \mathrm{Rs}$, shape the output of motor neurons through activation of these "reciprocal" and "recurrent" inhibitory pathways. Studies on spinal cord reflexes in the cat, using extracellular recording techniques, largely 
defined these circuits in the early part of the 20th century (Creed et al., 1932). Later, application of intracellular recording to spinal motoneurons in the 1950-1960s further refined our understanding of this circuitry.

\section{CENTRAL INHIBITORY SYNAPSES AND THE CHEMICAL HYPOTHESIS OF SYNAPTIC TRANSMISSION}

During the 1940s and early 1950s intense debate raged about the nature of synaptic transmission within the CNS (was it electrical or chemical?) and, to a lesser extent, what neurotransmitters and receptors were involved. The Australian Nobel Laureate Sir John (Jack) Eccles was an outspoken supporter of the electrical hypothesis of synaptic transmission, which he proposed involved direct transfer of electrical potentials between neurons (Brooks and Eccles, 1947; Eccles, 1949; Burke, 2006; Stuart and Pierce, 2006). Alternatively, those who worked on peripheral synapses, such as Sir Henry Dale, supported a chemical hypothesis (Dale, 1934). Indeed, for peripheral synapses at autonomic ganglia and neuromuscular junctions a candidate neurotransmitter, acetylcholine, had been proposed and this idea was even accepted by Eccles in the late 40s (Eccles, 1949).

For central synapses, an electrical theory of synaptic transmission had been considered to explain the extracellular potentials recorded in motoneuron pools or ventral roots following stimulation of synergist muscle nerves (i.e., monosynaptic excitation). According to the electrical hypothesis, presynaptic action potentials in synaptic endings could depolarize motoneurons by the "transfer of electric charges at the contact." However, these ideas could only be truly tested when motoneurons were impaled with intracellular microelectrodes in the early 1950s (Brock et al., 1952b; Woodbury and Patton, 1952). The development of this technique meant membrane potential and conductance changes across the motoneuron membrane could be directly measured (Figure 2). For excitatory monosynaptic connections, many of the previously established parameters using extracellular electrodes, such as central latency and times for synaptic delay, were confirmed. Accordingly, the electrical hypothesis adequately explained the results of experiments on excitatory monosynaptic connections between 1a afferents and synergist motoneurons (Figure 2B).

The electrical hypothesis was more difficult to apply in experiments where stimulation of muscle nerves inhibited motoneuron activity. Lloyd and co-workers had introduced the term "direct inhibition" for the reduced discharge observed in motoneurons after stimulating 1a afferents innervating antagonist muscles (Lloyd, 1946). For example, the monosynaptic reflex discharge generated in biceps-semitendinosus motoneurons could be inhibited if the nerve to the quadriceps was stimulated immediately $(\sim 0.5-1 \mathrm{~ms})$ beforehand. This form of inhibition was subsequently termed "reciprocal inhibition" to better reflect the function of this pathway in stretch reflexes involving antagonistic pairs of muscles (Jankowska et al., 1965). Eccles later proposed the so-called "Golgi hypothesis" to explain reciprocal inhibition, whereby inhibitory fibers terminated on interneurons called Golgi cells, which sent their short axons to contact the inhibited motoneurons. These Golgi cells supposedly caused hyperpolarization by acting as sinks for excitatory currents (Brooks and Eccles, 1947).
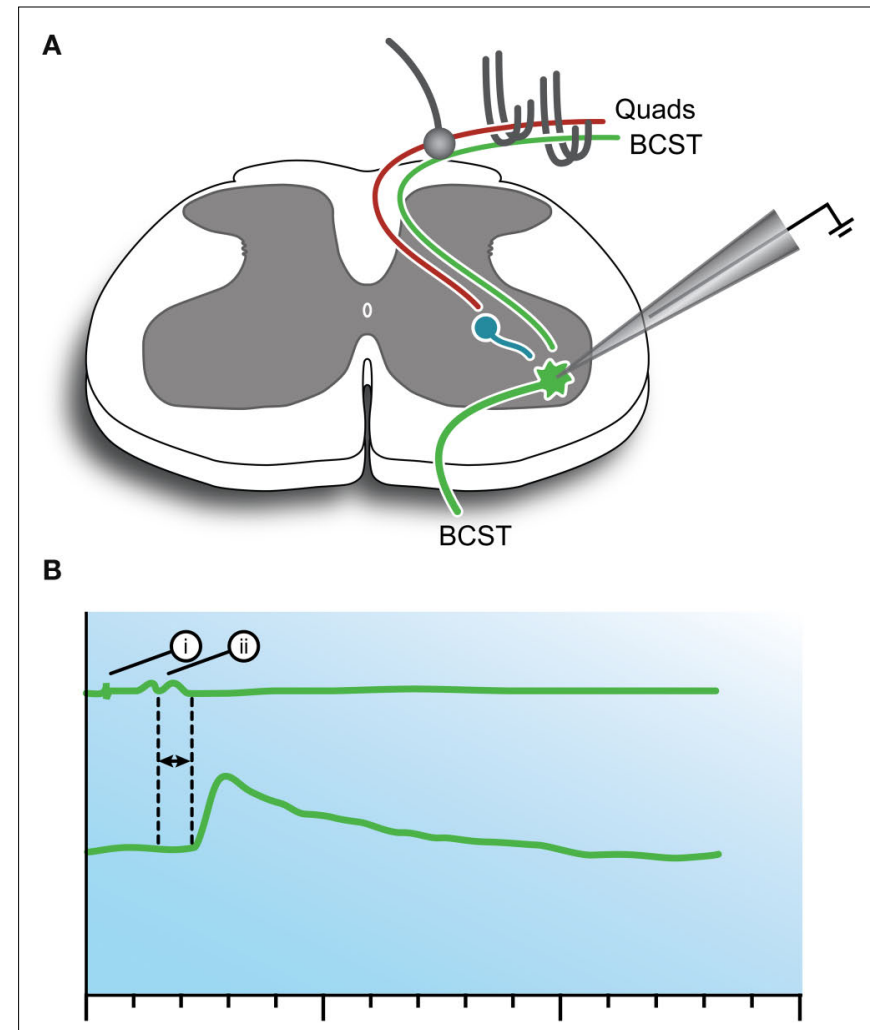

C

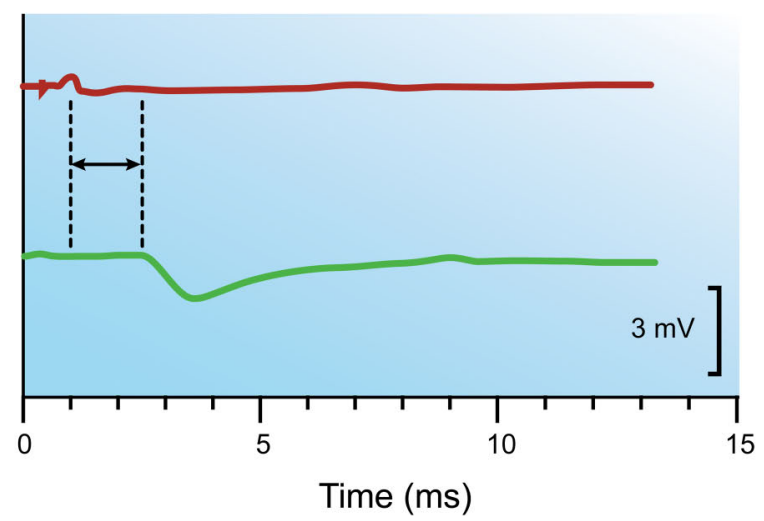

FIGURE 2 | Intracellular responses recorded in motoneurons after stimulation of monosynaptic excitatory and reciprocal inhibitory pathways. (A) Schematic showing the experimental configuration. A motoneuron innervating BCST is impaled with an intracellular recording electrode. Stimulating electrodes can activate either agonist (BCST) or antagonist (Quads) 1a afferents within muscle nerves. Arrival of the afferent volley at the dorsal root entry zone is monitored with a ball electrode. (B) Upper trace shows recording from ball electrode and indicates when a stimulus is delivered to the agonist muscle nerve (i) and when the volley arrives at spinal cord (ii). Bottom trace shows resulting depolarization in the motoneuron (ie, an EPSP). This response is characteristic of the monosynaptic excitatory pathway and shows the short latency between the dorsal root volley and beginning of the synaptic response (horizontal arrows). (C) Upper trace indicates when a stimulus is delivered to the antagonist muscle nerve and when the volley arrives at the spinal cord. Bottom trace shows hyperpolarization in the motoneuron (ie, an IPSP). Hyperpolarization and a longer latency (horizontal arrows) is characteristic of the reciprocal inhibitory pathway. Modified with permission from Figure 12 in Brock et al. (1952b). 
The above views on inhibitory synaptic transmission were examined in greater detail when motoneurons were impaled with intracellular electrodes in the early 1950s. When reciprocal inhibition was studied with an intracellular microelectrode, the result was intriguing - the interior of the recorded motoneuron became transiently "more" negative to earth (Figure 2C). Such hyperpolarization was also noted during "secondary inhibition", the inhibition observed in extensor motoneurons after stimulating cutaneous afferents. This hyperpolarizing response was first reported in abstract form (Brock et al., 1952a). In this landmark abstract the authors stated "an electrical explanation of inhibitory synaptic action seems to be precluded" and even proposed that "inhibition is caused by a specific chemical mediator". Later in the same year, in what is now the classic manuscript on the beginning of intracellular recording in neurons, they studied hyperpolarization in more detail and concluded "...the potential change observed is directly opposite to that predicted by the Golgi-cell hypothesis, which is thereby falsified" (Brock et al., 1952b, p. 452). In the final sentence of the results section they proposed the inhibitory effect was generated in the motoneuron and not by the Golgi cell and wrote "It may therefore be concluded that inhibitory synaptic action is mediated by a specific transmitter substance that is liberated from the inhibitory synaptic knobs and causes an increase in polarization of the subjacent membrane of the motoneurone" (p. 452).

As a result of these intracellular recordings, the now familiar terms EPSP (excitatory postsynaptic potential) and IPSP (inhibitory postsynaptic potential) were proposed in a later paper to describe the transient depolarizing and hyperpolarizing responses observed in motoneurons following activation of excitatory and inhibitory synapses, respectively (Bradley et al., 1953). To some extent, the time $(0.3-0.4 \mathrm{~ms})$ we now assign to synaptic delay also evolved from these experiments on EPSPs and IPSPs. The longer central conduction times for reciprocal IPSPs vs. monosynaptic EPSPs $(0.7$ vs. $0.4 \mathrm{~ms}$ ) could be explained by the presence of an intervening synapse, which took $\sim 0.3 \mathrm{~ms}$ to activate, on an interposed neuron (ie, the la interneuron; Figure 1B).

Thus, based on what we know today about GlyRs in spinal inhibitory pathways, it is clear that they played a critical role in the development of one of the major tenants of modern neuroscienceboth central and peripheral neurons communicate predominantly by releasing neurotransmitters from their axon terminals (ie, via chemical transmission).

\section{CENTRAL INHIBITION IS MEDIATED BY A CHLORIDE CHANNEL}

Having rapidly accepted the chemical hypothesis of synaptic transmission, Eccles and colleagues set out to determine how the "inhibitory transmitter substance" caused hyperpolarization of the postsynaptic membrane. The initial account of their findings was published in a relatively obscure journal, The Australian Journal of Science (Coombs et al., 1953), then later expanded (Eccles et al., 1954; Coombs et al., 1955b). They first noted that IPSPs generated after stimulation of the reciprocal inhibitory pathway were quite brief, with rise times and decay time constants of $\sim 1 \mathrm{~ms}$ and $\sim 4 \mathrm{~ms}$, respectively. They concluded the underlying conductance change must be very rapid and be completed within $\sim 2 \mathrm{~ms}$. In vivo experiments undertaken almost four decades later using single electrode voltage clamp techniques on cat motor neurons confirmed the currents (ie, IPSCs) mediating both reciprocal and recurrent inhibition are indeed brief - they have decay times of 1.0 and $0.8 \mathrm{~ms}$ at $37^{\circ} \mathrm{C}$, respectively (Stuart and Redman, 1990). These values also match those from voltage clamped glycine-mediated IPSCs in other spinal cord neurons after appropriate allowances for recording temperature (Takahashi and Momiyama, 1991).

Eccles and colleagues also observed that the amplitude of the reciprocal IPSP decreased over time (a few minutes) and eventually "reversed" in polarity to produce a depolarizing potential (ie, an EPSP). Importantly, this reversal only occurred when the intracellular microelectrode was filled with $\mathrm{KCl}$, but never when microelectrodes contained $\mathrm{KSO}_{4}$ or $\mathrm{KPO}_{4}$. They proposed the reversal of the IPSP was due to diffusion of chloride ions into the recorded neuron from the highly concentrated $\mathrm{KCl}$ solution $(3 \mathrm{M})$ within the microelectrode (Figure 3B). Further evidence for a chloridemediated mechanism was provided by experiments where diffusion of chloride ions into the motoneuron was accelerated by passing negative current into the microelectrode. In such experiments, the polarity reversal was the same, but occurred more rapidly. These effects, however, were never observed on EPSPs generated when stimulating the monosynaptic excitatory pathway (Figure 2). After making these observations they concluded "The simplest explanation for this effect would be that the inhibitory transmitter substance causes the subsequent postsynaptic membrane to become highly permeable to chloride" (Coombs et al., 1953, p. 2).

They also suggested that a metabolic "pump" must exist for the ejection of chloride ions, much like the sodium-potassium pump proposed by Hodgkin and colleagues within axons and muscle (Hodgkin, 1951; Hodgkin and Keynes, 1953). The identity of these chloride pumps is now well established and, importantly, their activity is highly mutable. For example, during development, pump activity alters intracellular chloride concentration and changes the polarity of GlyR currents from excitatory to inhibitory (Nakayama et al., 2002). This mechanism has also been shown to be important in certain pain states whereby intracellular chloride $\left[\mathrm{Cl}^{-}\right]_{\mathrm{i}}$ can increase and subsequently cause GlyR current depolarization. This effectively increases the excitability of neurons involved in nociceptive processing and alters pain thresholds (Coull et al., 2003).

More heroic experiments subsequently used double-barreled microelectrodes to impale motoneurons (Figure 3C). One barrel was for recording and the other for passing current and manipulating membrane potential (Coombs et al., 1955a). This approach allowed the study of synaptic potentials (both EPSPs and IPSPs) over a wide range of membrane potentials, as is routinely accomplished today with patch clamp techniques. These experiments showed both EPSPs and IPSPs could be reversed by altering membrane potential. Reversal was routinely observed for IPSPs, however, for EPSPs this was usually not achieved using double-barreled microelectrodes because of capacitive coupling between the two closely spaced electrode tips. Later work using two separate electrodes to impale motoneurons succeeded in reversing EPSPs and confirmed a reversal potential of $0-10 \mathrm{mV}$ for 1a-mediated EPSPs (Engberg and Marshall, 1979). However, the most important result from early experiments was that EPSPs and IPSPs reversed at vastly different potentials ( $\sim 0$ and $-80 \mathrm{mV}$, respectively). This confirmed that 


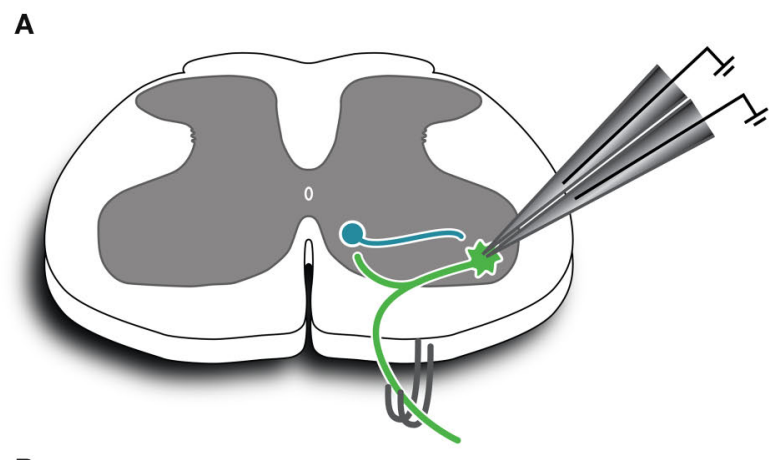

B
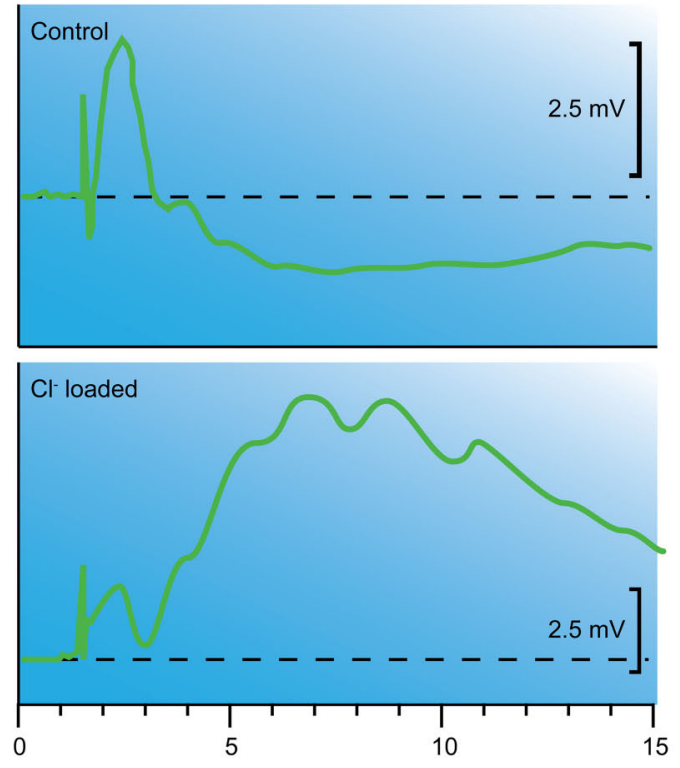

Time (ms)

FIGURE 3 | Inhibitory synaptic transmission is mediated by chloride ions. (A) Schematic showing the Renshaw cell circuit and recording configuration. The recurrent inhibitory pathway is activated, by stimulating muscle nerves or ventral roots. (B) Recurrent IPSP recorded with a $\mathrm{KCl}$-filled microelectrode before (upper trace) and after (lower trace) chloride ions have diffused out of the recording electrode into the motoneuron cytosol. Note, the IPSP has reversed (i.e., converted to an EPSP) after chloride loading. (C) Another experiment where recurrent IPSPs were recorded at several membrane potentials using a
C

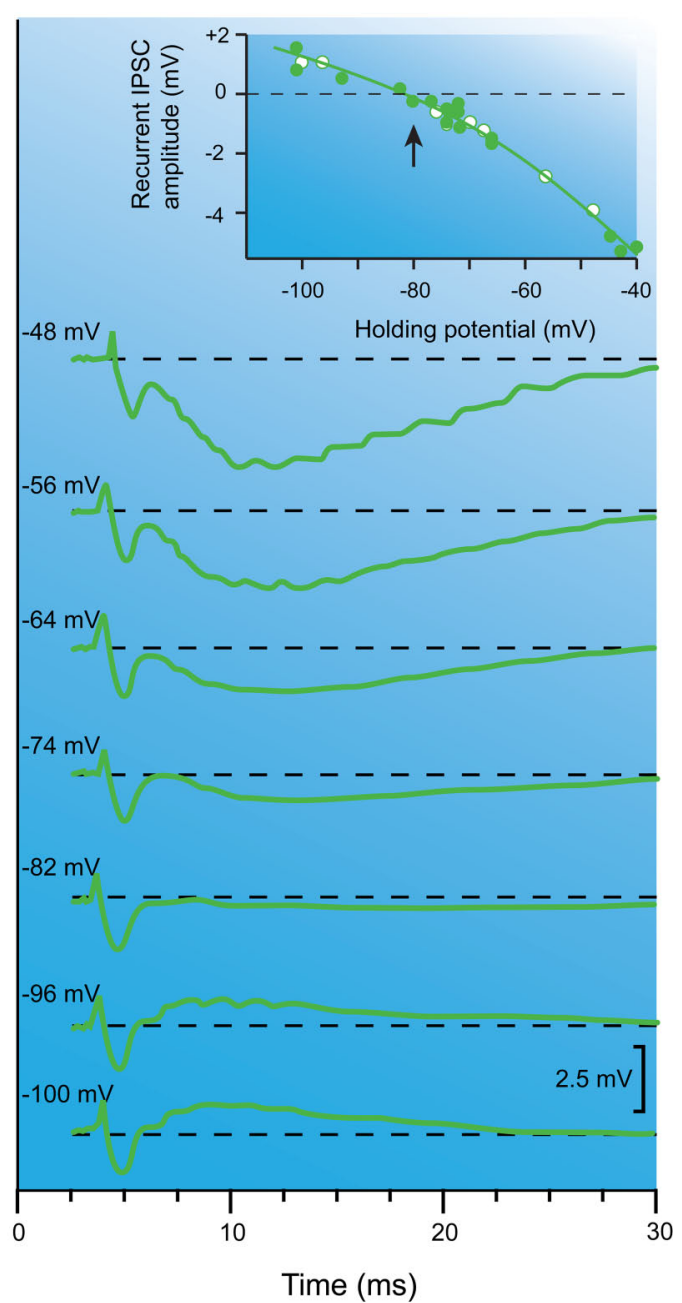

double-barreled intracellular microelectrode (dashed line equals baseline). One barrel recorded membrane potential and the other was used to inject current and control/hold membrane potential. In these experiments a $\mathrm{NaSO}_{4}$ internal solution was used to avoid chloride loading (as shown in B). Note the polarity of the response varies with holding potential. The inset shows a plot of the recurrent IPSC amplitude vs. holding potential. The IPSP reversed at $-80 \mathrm{mV}$, which approximates the equilibrium potential for chloride ions in CNS neurons. Modified with permission from Figures 1, 2 and 4 in Eccles et al. (1954).
EPSPs and IPSPs were due to the flow of different types of ions. Calculations based on the Nernst equation for the diffusion of ions across a semi-permeable membrane suggested that the intracellular concentration of chloride was about 7-12 mM (assuming extracellular chloride $\left[\mathrm{Cl}^{-}\right]_{\mathrm{o}}$ was $110 \mathrm{mM}$, the same as plasma). Subsequent in vivo and in vitro experiments on cat and rat motoneurons have confirmed that $\left[\mathrm{Cl}^{-}\right]_{\mathrm{i}}$ is $\sim 6.5 \mathrm{mM}$ when $\left[\mathrm{Cl}^{-}\right]_{\mathrm{o}}$ is $134 \mathrm{mM}$ (Forsythe and Redman, 1988; Stuart and Redman, 1990).

In summary, these insightful experiments suggested that inhibitory synaptic transmission was mediated by a chloride conductance; that chloride ions were not equally distributed across the cell membrane; and that a membrane pump (ie, a chloride transporter) must exist to maintain the chloride gradient.

\section{STRYCHNINE AS A SELECTIVE INHIBITOR OF CENTRAL INHIBITION}

Sherrington and colleagues were the first to analyze the effects of sub-convulsive doses of strychnine on spinal cord reflexes in anesthetized cats (Owen and Sherrington, 1911). They showed strychnine reversed spinal cord reflexes, so that inhibitory reflexes became excitatory. This fit nicely with the well known convulsive effects of strychnine poisoning. In the conclusion of their paper, they proposed that strychnine "transformed the process of central inhibition into one of central excitation" (p. 240). Based on the types of experiments undertaken at the time, this explanation was entirely plausible as they were studying ventral root reflexes, driven by activity in both excitatory and inhibitory pathways (see Figure 1). Later experiments employing excitation of either 
pure excitatory or inhibitory pathways showed convincingly that strychnine only affected inhibitory pathways (Bradley et al., 1953).

These experiments provided further support for a "chemical transmitting substance" (p. 478) that mediated central inhibition. For example, because the effect of strychnine was so rapid (within seconds following IV injection), Eccles and colleagues proposed "the most probable explanation is that strychnine and the inhibitory transmitter compete for the same steric configurations on the inhibitory postsynaptic membrane" (Bradley et al., 1953, p. 487). Similar mechanisms had been proposed to explain the action of curare on cholinergic synaptic transmission at peripheral synapses (Fatt and Katz, 1951). The final insightful prediction in their landmark 1953 paper came at the end of the discussion where they proposed "...it is evident that strychnine will provide a valuable means of investigating the nature of central inhibition." Indeed, this has proved to be the case. Strychnine subsequently played an important role in purifying and cloning the GlyR (Grenningloh et al., 1987), and confirming the involvement of GlyRs or $\mathrm{GABA}_{\mathrm{A}}$ Rs in many neural pathways (Lim et al., 1999; O’Brien and Berger, 1999; Russier et al., 2002; Graham et al., 2003).

\section{RECURRENT INHIBITION: THE RENSHAW CELL CIRCUIT}

In the 1940s, Birdsey Renshaw used extracellular recording techniques to show that activity in motoneurons could inhibit the discharge of motoneurons within the same, or surrounding motoneuron pools (Renshaw, 1941, 1946). This work built on earlier work, which showed antidromic stimulation of motor axons inhibited rhythmic firing in motoneurons (Eccles and Hoff, 1932). Experimentally, this form of inhibition was most easily observed in preparations with cut dorsal roots (i.e., deafferented; Figures 1B,3A and 4A) where stimulation of ventral roots (ie, antidromic stimulation) produced prolonged inhibition of motoneuron discharge. Importantly, the onset (or latency) of this inhibitory response was consistent with the involvement of a synapse on an interposed interneuron, as had been proposed for the reciprocal inhibitory pathway. The time course of the inhibitory response, however, was much longer than that observed during reciprocal inhibition.

During investigation of this inhibitory pathway Renshaw made extracellular recordings from a group of neurons located ventromedial to the motoneuron pools (Renshaw, 1946). These neurons discharged in characteristic high frequency bursts $(\sim 30-50 \mathrm{~ms}$ duration with instantaneous firing frequencies $>1000 \mathrm{~Hz})$ following a single supra-threshold shock to ventral roots (Figure 4B; upper panel). Renshaw speculated that axon collaterals from motor neurons, which were known to anatomists (Cajal, 1909), excited a population of interneurons whose axons contacted motoneurons and inhibited them. At the time the mechanism surrounding this inhibition focused on the involvement of electric fields between neurons - recall the electrical theory of synaptic transmission was favored at central synapses in the 1940s. This interposed interneuron was later termed the Renshaw cell (Eccles et al., 1954) in honor of the scientist who proposed this inhibitory circuit. Ironically, Renshaw died tragically in 1948 from poliomyelitis, a disease that attacks motoneurons.

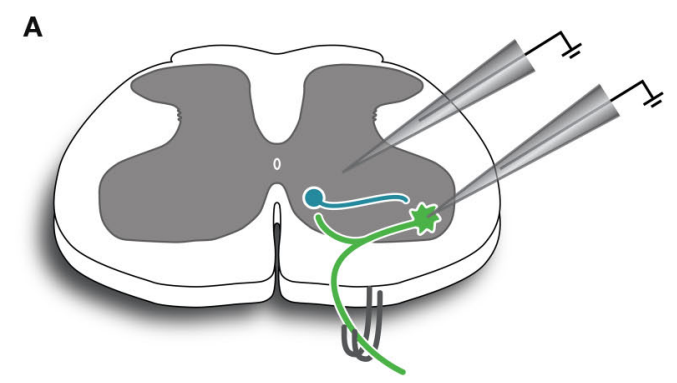

B
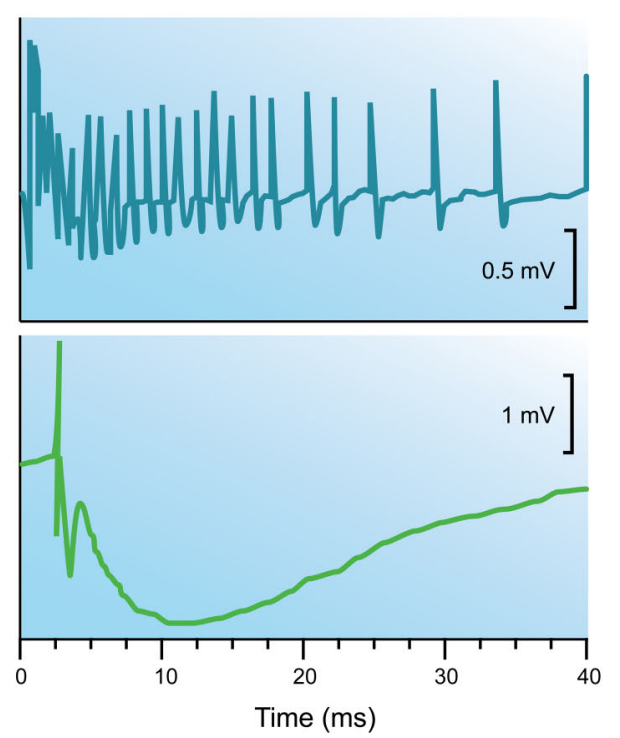

C

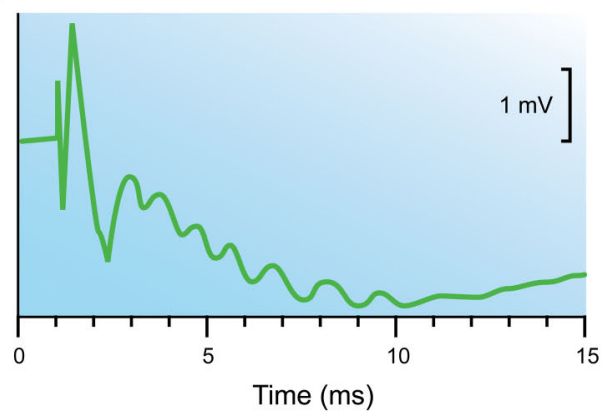

FIGURE 4 | Electrophysiological features of the recurrent inhibitory pathway. (A) Schematic showing the Renshaw cell circuit and recording methods. The recurrent pathway is activated by stimulating muscle nerves or ventral roots in deafferented preparations. In some experiments extracellular recordings are made from Renshaw cells located on the ventro-medial border of the ventral horn. In other experiments intracellular recordings are made from motoneurons. (B) Upper trace shows the extracellular response in a Renshaw cell following a single ventral root volley. Note the prolonged discharge. Lower trace shows an intracellularly recorded response in a motoneuron after a single ventral root volley. Note the long time course of the hyperpolarization compared with the response observed after stimulation of the reciprocal inhibitory pathway (Figure 2C). (C) Response shown in panel (B) lower on an expanded timescale. Note the prominent "ripples" in the rising phase of the hyperpolarization indicating the arrival of multiple high frequency inhibitory inputs from Renshaw cells. Modified with permission from Figures 3 and 12 in Eccles et al. (1954). 
Both Renshaw and Eccles had difficulty assigning a functional role to the recurrent inhibitory pathway other than "a generalized suppressor function" (p. 558) and that the circuit could be important for limiting intense motoneuron discharge, as occurs during convulsions (Eccles et al., 1954). This suppressor function is consistent with the motor disturbances (tremor and spasticity) exhibited by mutant mice where glycinergic inhibitory synapses, including those from Renshaw cells to motoneurons, are severely disrupted (Rajendra and Schofield, 1995; Simon, 1997). To this day the Renshaw cell remains one of the most studied interneurons in the mammalian CNS, and the Renshaw pathway serves as a classic example of an "inhibitory" or negative-feedback circuit involving GlyRs (Windhorst, 1996; Gonzalez-Forero and Alvarez, 2005).

As with monosynaptic and reciprocal inhibitory pathways, the introduction of intracellular microelectrodes allowed the recurrent inhibitory circuit to be examined in more detail and, importantly, test whether observations made on reciprocal inhibition applied to recurrent inhibition (Figures 1A,B). Two major studies, which should be compulsory reading for new GlyR biologists, suggested similar mechanisms operated in the recurrent inhibitory pathway (Eccles et al., 1954; Coombs et al., 1955c). An IPSP could be intracellularly recorded in motoneurons following stimulation of muscle nerves or ventral roots in deafferented preparations (Figure 4B; lower panel). The latency of this response, measured from the arrival of an antidromic volley in the spinal cord and the onset of the IPSP, ranged from 1.1 to $1.8 \mathrm{~ms}$ - values that matched the central delay for reciprocal inhibition (Eccles et al., 1956a). The IPSPs often exhibited high frequency ripples on their rising phase and peaks (Figure 4C). This suggested convergent inputs, from neurons discharging at high frequencies, contributed to the long time course of the recurrent IPSP. These recurrent IPSPs could be reversed by passing negative current through $\mathrm{KCl}$-filled electrodes (Figure 3B), or by manipulating membrane potential by current injection (Figure 3C), as was the case for reciprocal inhibition (Bradley et al., 1953; Eccles et al., 1954). Finally, intravenous injection of strychnine dramatically reduced the amplitude of the IPSP, as it did for reciprocal inhibitory connections. Thus, by the mid 50s it was clear that a similar neurotransmitter was responsible for the reciprocal and recurrent IPSP in spinal motor neurons.

\section{THE SEARCH FOR THE INHIBITORY TRANSMITTER SUBSTANCE}

By the mid 50s it was generally accepted that the inhibitory transmitter substance in the cat spinal cord caused permeability changes in the sub-synaptic membrane of motoneurons, and the resultant ion fluxes produced membrane hyperpolarization (Coombs et al., 1955c). Several rules pertaining to inhibitory synaptic transmission in the spinal cord were, for the most part, accepted at that time: (1) inhibitory synaptic transmission was chemically mediated; (2) both reciprocal and recurrent spinal inhibitory pathways involved a chloride conductance that reversed just below or near resting membrane potential; (3) inhibitory synaptic transmission could be markedly reduced by vascular administration of the convulsant strychnine; and (4) anatomical and electrophysiological evidence suggested clusters of neurons close to inhibited motor neurons were likely to release an inhibitory transmitter substance.
The initial search for chemical transmitter substances in the spinal cord used extracellular recordings and activation of the excitatory and inhibitory pathways shown in Figure 1. These early experiments, which measured responses in neurons after vascular administration of drugs, produced inconsistent results across laboratories and various explanations were proposed (Curtis and Eccles, 1958b). For example, it was not clear if drugs delivered into the vasculature acted within the CNS or on peripheral receptors (e.g., muscle spindles and tendon organs in muscles). There was also concern that various diffusion barriers might prevent substances getting into the CNS (Curtis and Eccles, 1958a). A significant breakthrough came with the development of multi-barreled electrodes, which allowed drugs to be delivered in the close vicinity of recorded neurons, and by extension to synapses on their somas and proximal dendrites (Figure 5A). These electrodes consisted of a central extracellular recording electrode, surrounded by several barrels that could apply drugs by the controlled application of current (now termed iontophoresis; (Curtis and Eccles, 1958b). The new electrodes employed ideas from earlier experiments on acetylcholine responses at neuromuscular junctions where a "breaking current" was applied to control the outflow of acetylcholine from an electrode (Del Castillo and Katz, 1955). Depending on the charge of the drug under investigation, positive or negative iontophoretic currents could be used to drive them out of electrodes. Application times could be precisely controlled, however, the exact concentrations achieved in the vicinity of recorded neurons could only be inferred, and for technical reasons, was sometimes poorly controlled.

The search for the inhibitory transmitter in the spinal cord was initially driven by the view that any substance that acts as a neurotransmitter must be concentrated in the tissue where it exerts its effect. For inhibition, the amino acid, GABA, was an obvious transmitter candidate. GABA was concentrated in brain tissue (Bazemore et al., 1956), and importantly it depressed spiking in cortical neurons (Purpura et al., 1957). The depressant action of GABA in the mammalian CNS also paralleled that of the "natural transmitter substance" at a well-understood inhibitory synapse in the crayfish (Kuffler and Edwards, 1958). Based on these data, Curtis and colleagues examined the effects of GABA, and the structurally similar $\beta$-alanine, on the activity of neurons in the cat spinal cord (Curtis and Phillis, 1958; Curtis et al., 1959). Using multi-barreled electrodes they showed iontophoretic application of GABA and $\beta$-alanine suppressed spiking, reduced EPSP and IPSP amplitude, and reduced electrical excitability in spinal neurons (ie, via shunting inhibition). On the occasions where they were able to make intracellular recordings in motoneurons, the application of either compound produced no significant changes in resting membrane potential. This contrasted markedly with the depolarization observed when excitatory transmitter candidates (aspartate and glutamate) were applied to motoneurons (Curtis et al., 1960). In interpreting their data, they stated "All evidence indicates that these substances have a non-specific depressant action upon the whole surface membrane of neurones, both the chemically activated sub-synaptic regions and the remaining electrically excited postsynaptic membrane" (p. 202). In later experiments they would modify this view (Curtis et al., 1968b), however, the failure of applied amino acids 
A

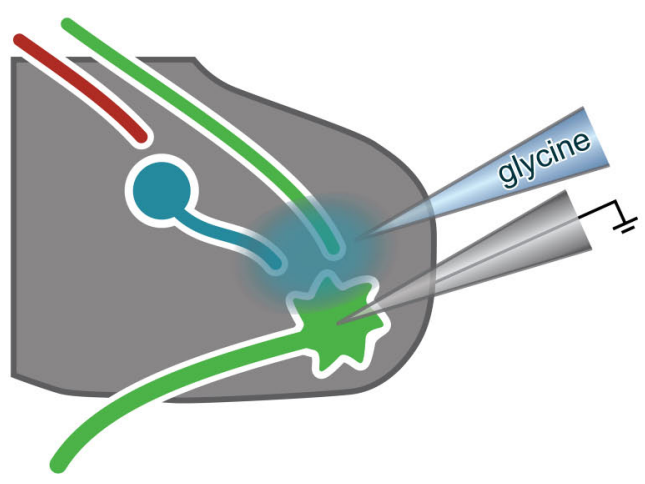

B

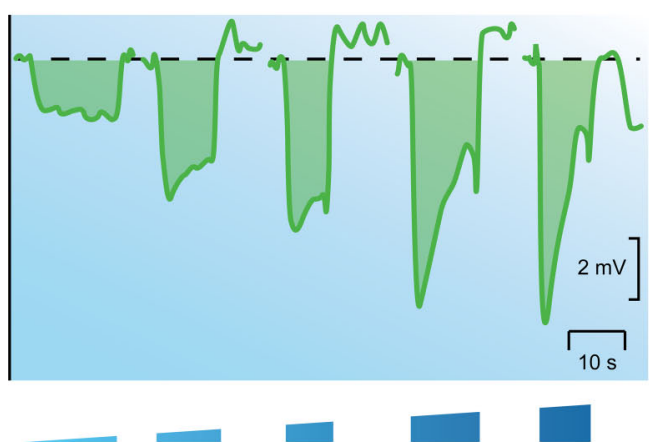

Glycine iontophoresis

C

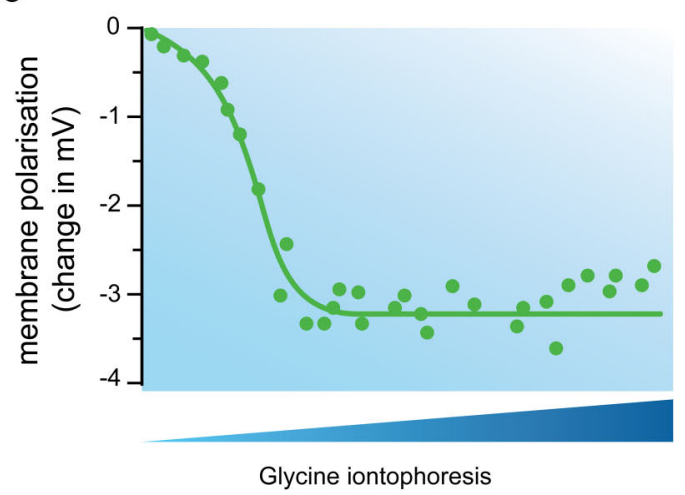

FIGURE 5 | Evidence that glycine is an inhibitory transmitter in the cat spinal cord. (A) Experimental setup showing electrodes used for extracellular iontophoresis of glycine, and intracellular recording of IPSPs in motoneurons.

(B) Schematic showing hyperpolarizing responses recorded in a motoneuron during increasing iontophoretically-driven glycine applications. (C) Plot of peak membrane hyperpolarization (from data in $\mathbf{B}$ ) in a motoneuron after iontophoretic application of glycine. Note the response increases to a plateau, despite continued increases in glycine iontophoresis. (D) Upper two traces show dorsal root potentials recorded during activation of the reciprocal inhibitory pathway (top trace), and the monosynaptic excitatory pathway (bottom trace). Lower trace

(GABA and $\beta$-alanine) to hyperpolarize motoneurons (like the synaptically released transmitter substance) meant in the early 1960 s the identity of the inhibitory neurotransmitter in the cat spinal cord was still unknown.
D

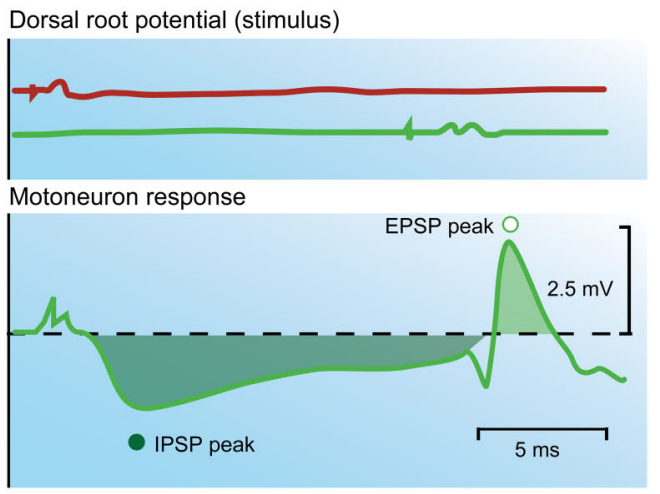

E

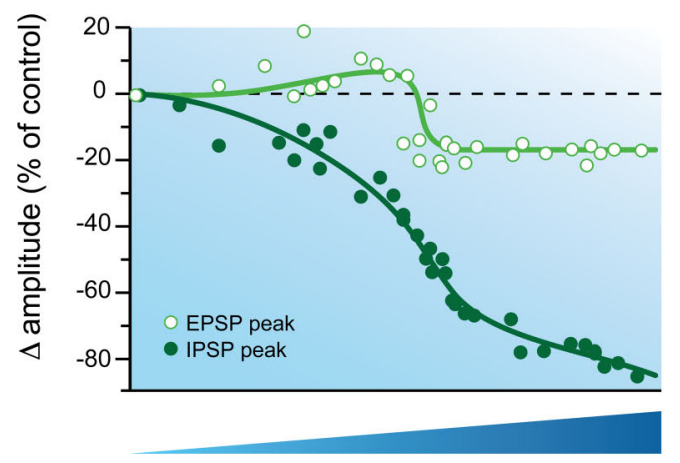

Glycine iontophoresis

$\mathbf{F}$

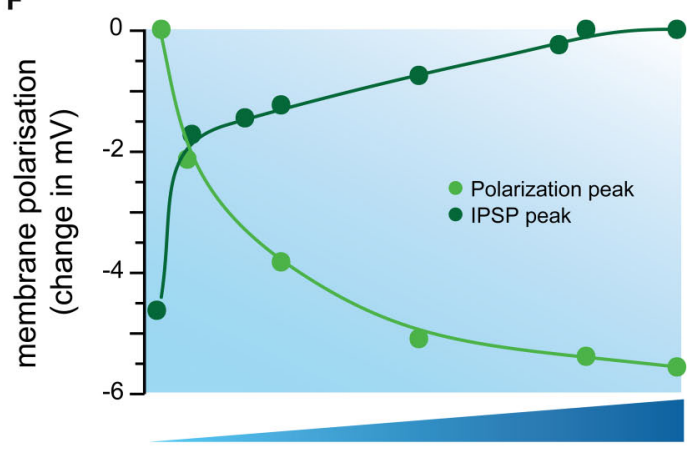

Glycine iontophoresis

shows the postsynaptic response (an IPSP followed by an EPSP) recorded in a motoneuron after stimulating the above inhibitory and excitatory pathways. (E) Plot of IPSP and EPSP peak amplitude (filled and open circles, respectively) during increasing iontophoresis of glycine. Note the amplitude of the IPSP is reduced far more than that of the EPSP. (F) Comparison of the effects of applied glycine on IPSP amplitude and membrane hyperpolarization. The IPSP amplitude (dark green circles) approaches zero as the level of membrane hyperpolarization approaches a plateau (light green circles). This experiment provided strong evidence that a similar process underlies the response to applied glycine and the IPSP. Modified with permission from Figures 4, 11 and 12 in Werman et al. (1968).

\section{GLYCINE IS AN INHIBITORY NEUROTRANSMITTER IN THE SPINAL CORD}

The possibility that glycine might also be an inhibitory transmitter evolved more slowly. It was an amino acid, like GABA and $\beta$-alanine, and was therefore included in early structure-activity studies on 
the effects of various compounds on neuron activity in the cat spinal cord (Curtis and Watkins, 1960). In surveying the effects of a large number of related amino acids of known chemical structure (50 "excitants" and 65 "depressants" listed in their Tables 1 and 2), Curtis and Watkins concluded that excitatory activity was associated with compounds possessing two acidic and one basic group, whereas depressant activity was associated with the presence of one acidic and one basic group. As specific chemical structures appeared to be linked with excitatory and inhibitory action, they also speculated on the structural features of the receptors for each type of transmitter, and the mechanisms by which excitatory and inhibitory transmitters might alter membrane permeability. In regard to the structural features of the receptor site they stated "The amino acid receptor can thus be considered to consist of an arrangement of fully or partially charged atoms or groups located within a specific region of the molecular framework of the membrane, to which region, molecules in the extracellular fluid have only limited access" (p. 133). They also proposed that binding of neurotransmitter to charged residues on the receptor could alter ionic permeability. To explain the different action of excitatory and inhibitory compounds on membrane potential they proposed only excitatory substances "result in the net entry of sodium ions into the cell, this accounting for the observed depolarization" (p. 136). These insights on the nature of ion channel behavior should seem remarkable to today's ion channel biologists who routinely use terms like charged residues, poor selectivity, and ion hydration.

During the 1960s, additional evidence accumulated for the role of glycine as an inhibitory transmitter. First, the extensive Curtis and Watkins (1960) survey had shown glycine was a depressant. Second, GABA was clearly not the only compound involved in inhibition, as vascular administration of strychnine had no effect on applied GABA, even though it was a potent inhibitor of IPSPs (Eccles et al., 1954; Curtis et al., 1959). Third, investigation of free amino acid levels in the spinal cord showed glycine levels actually exceeded those for the other candidate central transmitters, GABA and L-glutamate (Graham et al., 1967). Fourth, when glycine levels were analyzed in various regions of the cat spinal cord they were highest in the ventral horn where inhibitory interneurons were concentrated (Aprison and Werman, 1965). Accordingly, Aprison and Werman concluded "This pattern is considered to be compatible with a possible role for glycine as the major physiological postsynaptic spinal visceral inhibitory transmitter" (p. 2082). Additional support for their proposal came from studies involving manipulations that "killed off" spinal interneurons. Glycine levels in the ventral horn decreased and importantly glycine levels correlated with the extent of interneuron loss (Davidoff et al., 1967a,b). Thus, by the late 60 s considerable evidence suggested glycine was a candidate inhibitory transmitter in the cat spinal cord.

As the above evidence mounted, a series of sophisticated experiments by Werman et al. $(1967,1968)$ examined the mechanisms by which glycine might exert its effects). They developed a side-by-side electrode configuration that allowed simultaneous intracellular recording from motoneurons and extracellular iontophoresis of glycine (Figure 5). This electrode arrangement allowed comparison of IPSPs evoked by stimulating inhibitory pathways (reciprocal or recurrent) and responses to iontophoresed glycine (Figure 5B). The most relevant findings for GlyRs were: (1) appli- cation of glycine always produced a hyperpolarization $(\sim 3.7 \mathrm{mV}$; $n=27$ ) in motoneurons, and the magnitude of the hyperpolarization was inversely correlated with membrane potential; (2) as the iontophoretic current was increased (and by inference [glycine] $]_{\mathrm{o}}$ ) the magnitude of the hyperpolarization increased and plateaued (Figures 5B,C); (3) the hyperpolarization produced by glycine was associated with an increase in membrane conductance; and (4) as glycine application did not affect the threshold for action potential initiation, they concluded "glycine does not act on the voltagesensitive electrically excitable membrane" (p. 86).

Werman et al. $(1967,1968)$ then went on to examine the effects of glycine on evoked postsynaptic potentials (ie, EPSPs and IPSPs; Figure 5D). The effect of applied glycine on IPSP amplitude was dramatic and in some instances application of increasing concentrations of glycine could virtually abolish the IPSP (Figure 5E). In contrast iontophoresis of glycine at excitatory synapses only slightly reduced the amplitude of evoked EPSPs (Figure 5E). They suggested the differing effect of glycine on IPSPs and EPSPs was due to the location of inhibitory and excitatory synapses on motoneuron dendritic trees - IPSPs were generated close to the soma and applied glycine was more likely to affect these synapses and reduce driving force (such as via shunting inhibition). EPSPs in contrast were generated some distance from the soma and were largely unaffected. These observations fit nicely with ideas being developed at that time on the integrative action of IPSPs and EPSPs, and the ongoing competition between inhibitory and excitatory synapses for the control of membrane potential in motoneurons and other neurons with large dendritic trees (Curtis and Eccles, 1959; Rall, 1959, 1960).

The mechanisms whereby application of increasing concentrations of glycine could virtually abolish some IPSPs were examined in more detail by comparing the amplitude of evoked IPSPs (in the reciprocal pathway) and the hyperpolarization produced by increasing [glycine $]_{0}$. Both IPSP amplitude and hyperpolarization showed an initial rapid change, which plateaued as glycine concentration increased (Figure 5F). A similar relationship was observed when glycine concentrations were progressively decreased. Together, these experiments suggested that the process underlying the evoked IPSP and the glycine response occurred in parallel - i.e., the inhibitory transmitter and glycine had identical action at the postsynaptic membrane.

To further investigate the relationship between IPSPs and glycine-induce membrane hyperpolarization, Werman and colleagues made recordings with $\mathrm{KCl}$-filled electrodes and showed that both the IPSPs and responses to applied glycine could be converted to depolarizations (ie, they could be reversed). Importantly, the depolarizing IPSPs disappeared at the same membrane potential where the response to applied glycine was greatest. In their discussion they stated "glycine and the inhibitory transmitter activate the same molecular process in the postsynaptic membrane" (p. 92). Thus, if one considers the three textbook criteria for a substance to be considered a neurotransmitter (e.g., Chapter 15; Kandel et al., 2000), work in the late 1960's was close to confirming two of the major criteria for a substance to be recognized as a neurotransmitter: (1) presence - glycine is present where it should be; and (2) release and identity of action - its action on the postsynaptic membrane closely mimicked that of the naturally-occurring transmitter. The third criteria, a mechanism for removal, took longer to satisfy. 
In the late 1960's there was considerable interest in processes that terminated neurotransmitter action, especially mechanisms involving uptake, as had been described for GABA in the cerebral cortex (Iversen and Neal, 1968). Neal (1971), subsequently showed a system for glycine uptake existed in the spinal cord and could provide a mechanism for inactivating glycine at inhibitory synapses). Moreover, the mechanism exhibited some important properties of an active transport system - specifically, the uptake process showed considerable structural specificity as uptake of $\left[{ }^{14} \mathrm{C}\right]$-glycine was unaffected by high concentrations of related amino acids such as aspartate, glutamate, valine, and GABA. Later researchers took advantage of this high-affinity uptake system and used EM-autoradiography to demonstrate that $\left[{ }^{3} \mathrm{H}\right]$-glycine density was highest in putative inhibitory synaptic terminals containing elliptical and pleomorphic vesicles (Price et al., 1976). In the 1990's the identity and important role of the glycine transporters, which rapidly remove glycine from the synaptic cleft into glia and neurons (GLYT1 and GLYT2, respectively) was firmly established (Guastella et al., 1992; Liu et al., 1993).

The possibility that glycine was an inhibitory transmitter was also explored by testing the antagonistic properties of strychnine on glycine-mediated responses. By the late 1960s, its action was considered to be competitive and reversible because strychnine blocked the action of iontophoresed glycine (Curtis et al., 1968a,b, 1969). Intriguingly, while strychnine was clearly useful for distinguishing responses mediated by glycine, it did not affect the inhibitory action of GABA. Subsequent studies explored the role of other convulsants that were structurally related to the strychnine molecule (Curtis et al., 1970). One of these was the plant alkaloid, bicuculline. When this compound was iontophoresed onto continuously discharging ventral horn neurons it was found to reversibly inhibit the action of applied GABA, but not that of glycine (Figure 6). Other experiments had also confirmed that strychnine did not affect the action of iontophoresed GABA (Curtis et al., 1967). Many of these findings were confirmed later in other spinal pathways. For example, Game and Lodge used extracellular recording techniques to examine the effects of iontophoresed strychnine and bicuculline on inhibitory responses in dorsal horn cells evoked by volleys in myelinated cutaneous afferents. Strychnine abolished the "early" inhibitions, and bicuculline abolished the longer latency responses. The authors concluded glycine and GABA might play differing roles in mediating inhibition in sensory pathways (Game and Lodge, 1975).

Thus by 1970, glycine and GABA were considered potential neurotransmitters at inhibitory synapses in the reciprocal and recurrent pathways in the cat spinal cord, and the action of each could be distinguished by their selective blockers strychnine and bicuculline, respectively. Later work showed glycine is widely used by other classes of spinal neurons in the ventral and intermediate grey (Fyffe, 1991), and in the dorsal horn (Game and Lodge, 1975) of the cat spinal cord. This work set the scene for future investigations when each receptor was isolated, purified, cloned and studied in cell expression systems. As stated in a recent perspective on glutamate receptor biology, it is difficult to conceive how we could study inhibitory synaptic mechanisms without the routine use of blockers of the GlyR and GABA R (Krnjevic, 2005). For example, work in the 1980s used strychnine binding to isolate and purify GlyRs from mammalian brain and reveal that the receptor was composed of

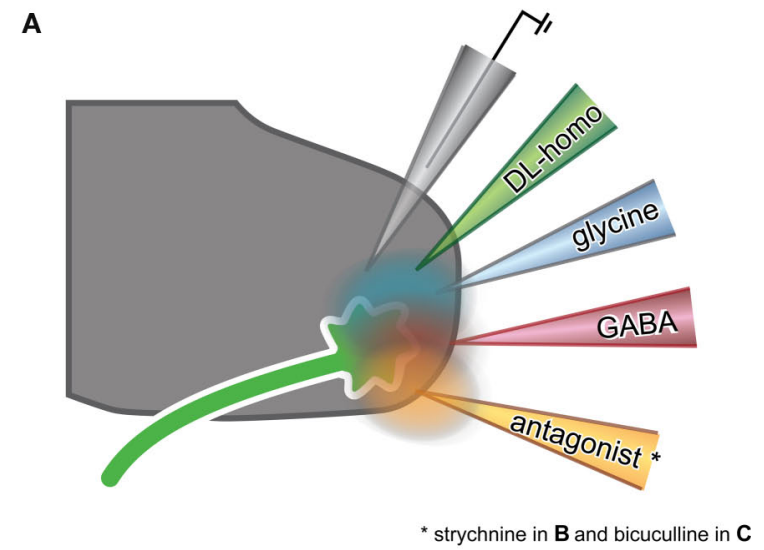

B

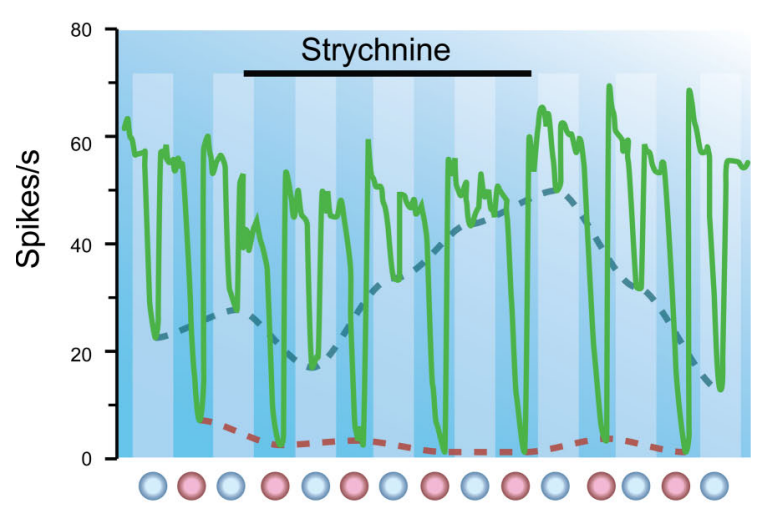

C

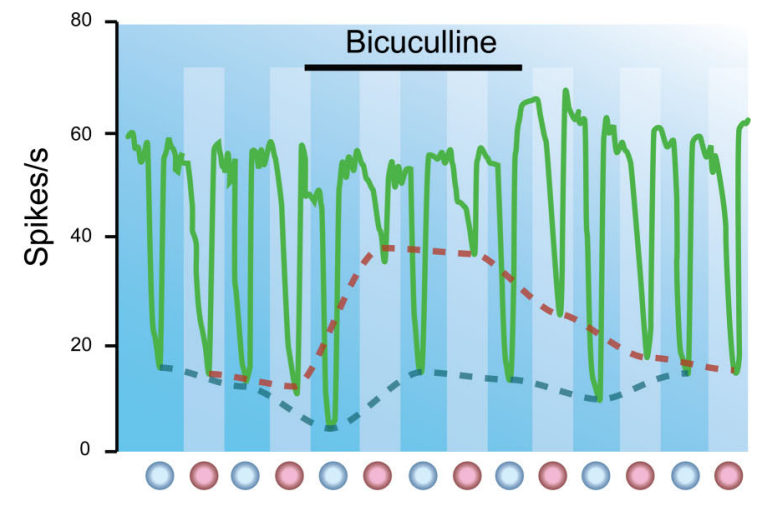

FIGURE 6 |The major inhibitory neurotransmitters can be distinguished pharmacologically. (A) Neurons are activated by continuous iontophoretic application of DL-homocysteic acid. Putative neurotransmitters and their antagonists, strychnine or bicuculline, are delivered via adjacent barrels in a multi-barrel electrode array. (B) Plot showing the effect of strychnine on inhibition of a Renshaw cell by applied glycine and GABA. Sustained iontophoresis of DL-homocysteic acid maintains a constant discharge rate in the target neuron. Glycine and GABA are alternatively applied at times indicated by red and blue dots, respectively. Strychnine application is indicated by horizontal bar. Note strychnine has a marked effect on glycine, but not GABA-mediated inhibition (red vs. blue dashed lines). (C) Similar experiment to (B), but strychnine application replaced by bicuculline. Note, bicuculline has a marked effect on GABA, but not glycine-mediated inhibition (blue vs. red dashed lines). These experiments showed strychnine and bicuculline could be used to distinguish glycine and GABA-mediated synaptic transmission. Modified with permission from Curtis et al. (1970). 
two membrane proteins of $48 \mathrm{kDa}$ and $56 \mathrm{kDa}$ - corresponding to $\alpha$ and $\beta$ subunits, respectively (Pfeiffer et al., 1982; Langosch et al., 1988). A larger 93-kDa protein, called gephyrin, also co-purified with the GlyR. We now know that gephyrin resides on the postsynaptic side of glycinergic synapses and is critical for clustering GlyRs under release sites (Triller et al., 1985). Now of course we know that glycine is used as a neurotransmitter by numerous classes of neurons, including dorsal horn neurons.

\section{OTHER ENDURING PRINCIPLES DISCOVERED WHEN STUDYING CENTRAL INHIBITION IN VIVO LOCATION OF GLYRS ON THE SOMATODENDRITC TREES}

As the mechanisms underlying central inhibition in the cat spinal cord were being defined, several other important contributions to our understanding of CNS function were also uncovered. For example, in the 60s and 70s there was considerable interest in how synapse location on the somas and dendritic trees of complicated central neurons, like motoneurons, influenced their integrative or input/output properties (Rall, 1977). At that time, motoneurons were the most accessible central neuron, and excitatory and inhibitory inputs to motoneurons could be studied (Figure 2). The early work of Eccles and colleagues (Brock et al., 1952b) on the reciprocal inhibitory pathway proposed inhibitory synapses were located close to the spike initiating region - at least in motoneurons. This assertion was based on the extreme sensitivity of the IPSPs to intracellular chloride concentration (Figure 3B).

Later, an elegant study by Fyffe and colleagues examined this proposal in more detail. Four major neuron types, $\alpha$ motoneurons and $\gamma$ motoneurons, la interneurons, and Renshaw cells, which together play a crucial role in spinal locomotor circuits, were electrophysiologically identified and intracellularly labeled with neurobiotin in cat spinal cord preparations (Alvarez et al., 1997). The distribution of presumptive GlyR clusters on somal, proximal and distal dendrites of each neuron type was quantified using immunohistochemistry for gephyrin, the protein that anchors GlyRs under synapses. Their data showed that GlyR cluster size and complexity generally increased with distance from the soma in $\alpha$ and $\gamma$ motoneurons and 1a interneurons. In contrast, Renshaw cells displayed large and morphologically complex clusters, concentrated on their somas and proximal dendrites. The presence of large GlyR clusters on the small Renshaw cells suggested a powerful spinal mechanism exists to "turn off" these cells and their contribution to recurrent inhibition. The abundance of GlyRs at distal synapses suggested GlyRs can not only provide powerful shunting inhibition (Curtis et al., 1959), but also fine-tune the effects of excitation on distal synapses. These data suggested that positioning of synapses on somatodendritic trees depends on the role of the neuron in spinal cord circuits. Thus, the original postulate of Eccles regarding synapse location needs to be modified to account for the role of a neuron in circuit function.

\section{DALE'S HYPOTHESIS AT CENTRAL SYNAPSES}

In a classic paper presented to the Royal Society in 1934, Sir Henry Dale summarized the major ideas on synaptic transmission that had evolved from experiments on peripheral synapses. Based on experiments on sensory nerves (involving the axon-reflex), he suggested knowing the identity of the neurotransmitter at an axon's peripheral terminal might provide insight into the nature of its central neurotransmitter. Specifically he stated "When we are dealing with two different endings of the same sensory neurone, the one peripheral and concerned with vasodilatation and the other at a central synapse, can we suppose that the discovery and identification of a chemical transmitter of axon-reflex vasodilatation would furnish a hint as to the nature of the transmission process at a central synapse?" (p. 329). Eccles later referred to Dale's hypothesis when studying recurrent inhibition and coined the term Dale's principle (Eccles et al., 1954). He stated "the same chemical transmitter is released from all the synaptic terminals of a neurone" (p. 559). The advent of intracellular recording techniques and the increasing interest in inhibitory synaptic transmission in spinal reflex pathways allowed Dale's ideas to be tested at synapses within the CNS. Eccles et al. (1956b) took up this quest and in a series of experiments from 1952-1956 asked "Do the branches of any one nerve cell exert an excitatory synaptic action on some neurones and an inhibitory action on others?").

The recurrent inhibitory circuit provided an ideal model to test Dale's hypothesis as it was well established that acetylcholine was the neurotransmitter at the neuromuscular junction and should therefore be released from motoneuron recurrent collaterals (Figure 1C). Eccles and colleagues showed the extracellular responses recorded in Renshaw cells after ventral root stimulation was often enhanced when cats were given acetylcholine (intra-arterially), depressed with a cholinergic blocker (dihydro- $\beta$-erythroidine; given IV), and prolonged when animals were given an anticholinesterase (usually eserine; given IV). Together, these data suggested the synapse between recurrent motor axon collaterals and Renshaw cells, indeed uses the same transmitter as the peripheral neuromuscular junction. This experiment provided the first support for Dale's hypothesis at a synapse within the CNS.

With time, Dale's hypothesis has perhaps become overly simplified to mean one neuron, one transmitter. Dale never stated a neuron secretes a single neurotransmitter, but rather that knowledge of the neurotransmitter released at one terminal might provide clues to that released at its other terminals. As so elegantly summarized by Strata and Harvey the problem lies with use of the term transmitter in the singular (Strata and Harvey, 1999). If we accept this view, Dale's ideas do not conflict with the now well-accepted idea of neurotransmitter co-release. For example, two recent studies have shown both glycine and GABA can be concentrated in the same vesicle in synaptic terminals, released together, and act on a mixed population of glycine and GABA receptors underneath a release site (Jonas et al., 1998; O’Brien and Berger, 1999). In addition to co-release, recent work has suggested glutamate and acetylcholine can be released at the synapse between motoneuron collaterals and the inhibitory Renshaw cell (Nishimaru et al., 2005). Significantly, this study also showed that while glutamate is released centrally it is not released at peripheral terminals. Thus, there can be differences in transmitter content and release at two synapses from the same neuron. These recent observations may violate some interpretations of Dales hypothesis, but they do not violate his original suggestion that that knowledge of the neurotransmitter released at one terminal of a neuron might provide clues to that released at its other terminals. In summary, the study of inhibitory mechanisms in the spinal cord has contributed significantly to this important debate about neurotransmitter co-release and release of different neurotransmitters at two terminals of the same neuron. 


\section{CONCLUSIONS}

This review has attempted to reflect on some of the important discoveries made in the cat lumbosacral spinal cord that underpin our current understanding of GlyR function and fast inhibitory synaptic transmission. These key observations and predictions were made during a golden age of in vivo spinal cord synaptic physiology in the 1950s-1960s and endure till this day. For example, we now accept that GlyRs mediate their effects via chemically mediated transmission, are chloride channels, are involved in spinal reciprocal and recurrent inhibition, can be selectively blocked by strychnine, can be distinguished from the GABA $\mathrm{R}$ by their insensitivity to bicuculline, play a crucial role in synaptic

\section{REFERENCES}

Alvarez, F. J., Dewey, D. E., Harrington, D. A., and Fyffe, R. E. (1997). Cell-type specific organization of glycine receptor clusters in the mammalian spinal cord. J. Comp. Neurol. 379, 150-170.

Aprison, M. H., and Werman, R. (1965). The distribution of glycine in cat spinal cord and roots. Life Sci. 4, 2075-2083.

Bazemore, A., Elliott, K. A., and Florey, E. (1956). Factor I and gammaaminobutyric acid. Nature 178, 1052-1053.

Becker, L., Hartenstein, B., Schenkel, J., Kuhse, J., Betz, H., and Weiher, H. (2000). Transient neuromotor phenotype in transgenic spastic mice expressing low levels of glycine receptor beta-subunit: an animal model of startle disease. Eur. J. Neurosci. 12, 27-32.

Biscoe, T. J., and Duchen, M. R. (1986). Synaptic physiology of spinal motoneurones of normal and spastic mice: an in vitro study. J. Physiol. (Lond.) 379, 275-292.

Bradley, K., Easton, D. M., and Eccles, J. C. (1953). An investigation of primary or direct inhibition. J. Physiol. (Lond.) 122, 474-488.

Brock, L. G., Coombs, J. S., and Eccles, J. C. (1952a). Synaptic excitation and inhibition. J. Physiol. (Lond.) 117, 8.

Brock, L. G., Coombs, J. S., and Eccles, J. C. (1952b). The recording of potentials from motoneurones with an intracellular electrode. J. Physiol. (Lond.) 117, 431-460.

Brooks, C. M., and Eccles, J. C. (1947). An electrical hypothesis of central inhibition. Nature 159, 760-764.

Burke, R. E. (2006). John Eccles' pioneering role in understanding central synaptic transmission. Prog. Neurobiol. 78, 173-188.

Cajal, S. R. (1909). Histologie du Systeme Nerveux de l'Homme et des Vertebres. Paris: Maloine.

Coombs, J. S., Eccles, J. C., and Fatt, P. (1953). The action of the inhibitory synaptic transmitter. Aust. J. Sci. 16, 1-6.

Coombs, J. S., Eccles, J. C., and Fatt, P. (1955a). Excitatory synaptic action in motoneurones. J. Physiol. (Lond.) 130, 374-395.

Coombs, J. S., Eccles, J. C., and Fatt, P. (1955b). The inhibitory suppression of reflex discharges from motoneurones. J. Physiol. (Lond.) 130, 396-413.

Coombs, J. S., Eccles, J. C., and Fatt, P. (1955c). The specificionic conductances and the ionic movements across the motoneuronal membrane that produce the inhibitory post-synaptic potential.J. Physiol. (Lond.) 130, 326-374.

Coull, J. A., Boudreau, D., Bachand, K., Prescott, S. A., Nault, F., Sik, A., De Koninck, P., and De Koninck, Y. (2003). Trans-synaptic shift in anion gradient in spinal lamina I neurons as a mechanism of neuropathic pain. Nature 424, 938-942.

Creed, R. S., Denny-Brown, D., Eccles, J. C., Liddell, E. G. T., and Sherrington, C. (1932). Reflex Acitivity of the Spinal Cord. London: Oxford University Press.

Curtis, D. R., Duggan, A. W., Felix, D., and Johnston, G. A. (1970). GABA, bicuculline and central inhibition. Nature 226, 1222-1224.

Curtis, D. R., Duggan, A.W., and Johnston, G. A. (1969). Glycine, strychnine, picrotoxin and spinal inhibition. Brain Res. 14, 759-762.

Curtis, D. R., and Eccles, J. C. (1959). The time courses of excitatory and inhibitory synaptic actions. J. Physiol. (Lond.) 145, 529-546.

Curtis, D. R., and Eccles, R. M. (1958a). The effect of diffusional barriers upon the pharmacology of cells within the central nervous system. J. Physiol. (Lond.) 141, 446-463.

Curtis, D. R., and Eccles, R. M. (1958b). The excitation of Renshaw cells by pharmacological agents applied electrophoretically. J. Physiol. (Lond.) 141, 435-445.

Curtis, D. R., Hosli, L., and Johnston, G.A. (1967). Inhibition of spinal neurons by glycine. Nature 215, 1502-1503.

Curtis, D. R., Hosli, L., and Johnston, G. A. (1968a). A pharmacological study of the depression of spinal neurones by glycine and related amino acids. Exp. Brain Res. 6, 1-18.

integration, and are often preferentially located near a neuron's trigger zone. We hope our narrative on this important era will encourage those interested in GlyR biology and inhibitory mechanisms to seek out some of the "classic" articles that document these discoveries.

\section{ACKNOWLEDGMENTS}

We thank Debbie Booth in the Faculty of Health Library for her tireless help locating references and Belinda Harris and Melissa Walsh for editing the final draft of the manuscript. This work was supported by NH\&MRC project grants (\#s 401244, 569206, 628765, 631000) and the Hunter Medical Research Institute.

Curtis, D. R.,Hosli,L., Johnston, G. A., and Johnston, I. H. (1968b). The hyperpolarization of spinal motoneurones by glycine and related amino acids. Exp. Brain Res. 5, 235-258.

Curtis, D. R., and Phillis, J. W. (1958) Gamma-Amino-n-butyric acid and spinal synaptic transmission. Nature $182,323$.

Curtis, D. R., Phillis, J. W., and Watkins, J. C. (1959). The depression of spinal neurones by gamma-amino-n-butyric acid and beta-alanine. J. Physiol. (Lond.) 146, 185-203.

Curtis, D. R., Phillis, J. W., and Watkins, J. C. (1960). The chemical excitation of spinal neurones by certain acidic amino acids. J. Physiol. (Lond.) 150, 656-682.

Curtis, D. R., and Watkins, J. C. (1960). The excitation and depression of spinal neurones by structurally related amino acids. J. Neurochem. 6, 117-141.

Dale, H. H. (1934). Pharmacology and nerve endings. Proc. R. Soc. Med. 28 , 319-332.

Davidoff, R. A., Graham, L. T. Jr., Shank, R. P., Werman, R., and Aprison, M. H. (1967a). Changes in amino acid concentrations associated with loss of spinal interneurons. J. Neurochem. 14, 1025-1031.

Davidoff, R. A., Shank, R. P., Graham, L. T. Jr., Aprison, M. H., and Werman, R. (1967b). Association of glycine with spinal interneurones. Nature 214 680-681.

Del Castillo, J., and Katz, B. (1955). On the localization of acetylcholine receptors. J. Physiol. (Lond.) 128, 157-181.

Eccles, J. C. (1949). A review and restatement of the electrical hypothesis of synaptic excitatory and inhibitory action. Arch. Sci. Physiol. (Paris) 3, 567-584.

Eccles, J. C., Fatt, P., and Koketsu, K. (1954). Cholinergic and inhibitory synapses in a pathway from motoraxon collaterals to motoneurones. J. Physiol. (Lond.) 126, 524-562.

Eccles, J. C., Fatt, P., and Landgren, S. (1956a). Central pathway for direct inhibitory action of impulses in largest afferent nerve fibres to muscle. $J$. Neurophysiol. 19, 75-98.
Eccles, J.C., Fatt, P., and Landgren, S. (1956b). The inhibitory pathway to motoneurones. Prog. Neurobiol. 2, 72-82.

Eccles, J. C., and Hoff, H. E. (1932). The rhythmic discharge of motoneurones. Proc. R. Soc. Lond., B, Biol. Sci. 110, 483-514.

Engberg, I., and Marshallm, K. C. (1979). Reversal potential for Ia excitatory post synaptic potentials in spinal motoneurones of cats. Neuroscience 4, 1583-1591.

Fatt, P., and Katz, B. (1951). An analysis of the end-plate potential recorded with an intracellular electrode. J. Physiol. (Lond.) 115, 320-370.

Floeter, M. K., and Hallett, M. (1993). Glycine receptors: a startling connection. Nat. Genet. 5, 319-320.

Forsythe, I. D., and Redman, S. J. (1988). The dependence of motoneurone membrane potential on extracellular ion concentrations studied in isolated rat spinal cord. J. Physiol. (Lond.) 404, 83-99.

Fyffe, R. E. (1991). Glycine-like immunoreactivity in synaptic boutons of identified inhibitory interneurons in the mammalian spinal cord. Brain Res. 547, 175-179.

Game, C. J., and Lodge, D. (1975). The pharmacology of the inhibition of dorsal horn neurones by impulses in myelinated cutaneous afferents in the cat. Exp. Brain Res. 23, 75-84.

Gonzalez-Forero,D., and Alvarez,F.J.(2005). Differential postnatal maturation of GABAA, glycine receptor, and mixed synaptic currents in Renshaw cells and ventral spinal interneurons. J. Neurosci. 25, 2010-2023.

Graham,B.A., Brichta,A.M., and Callister, R. J. (2007a). Moving from an averaged to specific view of spinal cord pain processing circuits. J. Neurophysiol. 98, 1057-1063.

Graham,B.A.,Brichta,A.M.,Schofield,P.R, and Callister, R. J.(2007b). Altered potassium channel function in the superficial dorsal horn of the spastic mouse. J. Physiol. (Lond.) 584, 121-136.

Graham, B.A., Schofield, P. R., Sah, P., and Callister, R. J. (2003). Altered inhibitory synaptic transmission in super- 
ficial dorsal horn neurones in spastic and oscillator mice. J. Physiol. (Lond.) 551, 905-916.

Graham, B. A., Schofield, P. R., Sah, P., Margrie, T. W., and Callister, R. J. (2006). Distinct physiological mechanisms underlie altered glycinergic synaptic transmission in the murine mutants spastic, spasmodic, and oscillator. J. Neurosci. 26, 4880-4890.

Graham, L. T. Jr., Shank, R. P., Werman, R., andAprison,M.H.(1967).Distribution of some synaptic transmitter suspects in cat spinal cord: glutamic acid, aspartic acid, gamma-aminobutyric acid, glycine and glutamine. J. Neurochem. 14, 465-472.

Grenningloh, G., Rienitz, A., Schmitt, B., Methfessel, C., Zensen, M., Beyreuther, K., Gundelfinger, E. D., and Betz, H. (1987). The strychninebinding subunit of the glycine receptor shows homology with nicotinic acetylcholine receptors. Nature 328, 215-220.

Guastella, J., Brecha, N., Weigmann, C., Lester, H. A., and Davidson, N. (1992). Cloning, expression, and localization of a rat brain high-affinity glycine transporter. Proc. Natl. Acad. Sci. U.S.A. 89, 7189-7193.

Hart, B. L. (1971). Facilitation by strychnine of reflex walking in spinal dogs. Physiol. Behav. 6, 627-628.

Hartenstein, B., Schenkel, J., Kuhse, J., Besenbeck, B., Kling, C., Becker, C. M., Betz, H., and Weiher, H. (1996). Low level expression of glycine receptor beta subunit transgene is sufficient for phenotype correction in spastic mice. EMBO J. 15, 1275-1282.

Harvey, R. J., Depner, U. B., Wassle, H., Ahmadi, S., Heindl, C., Reinold, H., Smart, T. G., Harvey, K., Schutz, B., Abo-Salem, O. M., Zimmer, A., Poisbeau, P., Welzl, H., Wolfer, D. P., Betz, H., Zeilhofer, H. U., and Muller, U. (2004). GlyR alpha3: an essential target for spinal PGE2-mediated inflammatory pain sensitization. Science 304, 884-887.

Hodgkin, A. L. (1951). The ionic basis of electrical activity in nerve and muscle. Biol. Rev. 26, 339-409.

Hodgkin, A. L., and Keynes, R. D. (1953). The mobility and diffusion coefficient of potassium in giant axons from Sepia. J. Physiol. 119, 513-528.

Iversen, L. L., and Neal, M. J. (1968). The uptake of [3H]GABA by slices of rat cerebral cortex. J. Neurochem. 15, 1141-1149.

Jankowska, E., Jukes, M. G., Lund, S., and Lundberg, A. (1965). Reciprocal innervation through interneuronal inhibition. Nature 206, 198-199.

Jonas, P., Bischofberger, J., and Sandkuhler, J. (1998). Corelease of two fast neu- rotransmitters at a central Synapse. Science 281, 419-424.

Kandel, E. R., Schwartz, J.H., and Jessell, T. M. (2000). Principles of Neural Science. New York: Elsevier.

Krnjevic, K. (2005). From 'soup physiology' to normal brain science. J. Physiol. (Lond.) 569, 1-2

Kuffler, S. W., and Edwards, C. (1958). Mechanism of gamma aminobutyric acid (GABA) action and its relation to synaptic inhibition. J. Neurophysiol. 21, 589-610.

Langosch, D., Thomas, L., and Betz, H. (1988). Conserved quarternary structure of ligand-gated ion channels: the postsynaptic glycine receptor is a pentamer. Proc. Natl. Acad. Sci. U.S.A. 85 7394-7398.

Legendre, P. (2001). The glycinergic inhibitory synapse. Cell. Mol. Life Sci. 58, 760-793.

Lim, R., Alvarez, F. J., and Walmsley, B. (1999). Quantal size is correlated with receptor cluster area at glycinergic synapses in the rat brainstem. J. Physiol. (Lond.) 516, 505-512.

Liu, Q. R., Lopez-Corcuera, B., Mandiyan, S., Nelson, H., and Nelson, N. (1993). Cloning and expression of a spinal cord- and brain-specific glycine transporter with novel structural features. J. Biol. Chem. 268, 22802-22808.

Lloyd, D. (1946). Facilitation and inhibition of spinal motoneurons. $J$. Neurophysiol. 9, 421-438.

Lynch,J.W.(2004).Molecular structure and function of the glycine receptor chloride channel. Physiol. Rev. 84, 1051-1095.

Lynch, J. W., and Callister, R. J. (2006). Glycine receptors: a new therapeutic target in pain pathways. Curr. Opin. Investig. Drugs 7, 48-53.

Mody, I., and Pearce, R. A. (2004) Diversity of inhibitory neurotransmission through GABAA receptors. Trends Neurosci. 27, 569-575.

Nakayama, K., Nishimaru, H., and Kudo, N. (2002). Basis of changes in left-right coordination of rhythmic motor activity during development in the rat spinal cord. J. Neurosci. 22, 10388-10398.

Neal, M. J. (1971). The uptake of [14C] glycine by slices of mammalian spinal cord. J. Physiol. (Lond.) 215, 103-117.

Nishimaru, H., Restrepo, C. E., Ryge, J., Yanagawa, Y., and Kiehn, O. (2005). Mammalian motor neurons corelease glutamate and acetylcholine at central synapses. Proc. Natl. Acad. Sci. U.S.A. 102, 5245-5249.

O’Brien, J. A., and Berger, A. J. (1999). Cotransmission of GABA and glycine to brain stem motoneurons. $J$ Neurophysiol. 82, 1638-1641.

Owen,A. G., and Sherrington, C. S. (1911). Observations on strychnine reversal. J. Physiol. (Lond.) 43, 232-241.
Pfeiffer, F., Graham, D., and Betz, H. (1982). Purification by affinity chromatography of the glycine receptor of rat spinal cord. J. Biol. Chem. 257, 9389-9393.

Pratt, C. A., and Jordan, L. M. (1987). Ia inhibitory interneurons and Renshaw cells as contributors to the spinal mechanisms of fictive locomotion. $J$. Neurophysiol. 57, 56-71.

Price, D. L., Stocks, A., Griffin, J. W. Young, A., and Peck, K. (1976) Glycine-specific synapses in rat spinal cord. Identification by electron microscope autoradiography. J. Cell Biol. 68, 389-395.

Purpura, D. P., Girado, M., and Grundfest, H. (1957). Selective blockade of excitatory synapses in the cat brain by gamma-aminobutyric acid. Science 125, 1200-1202.

Rajendra, S., and Schofield, P. R. (1995). Molecular mechanisms of inherited startle syndromes. Trends Neurosci. $18,80-82$.

Rall,W. (1959). Branching dendritic trees and motoneuron membrane resistivity. Exp. Neurol. 1, 491-527.

Rall, W. (1960). Membrane potential transients and membrane time constant of motoneurons. Exp. Neurol. 2 , 503-532.

Rall, W. (1977). “Core conductor theory and cable properties of neurons," in Handbook of Physiology: the Nervous System, Vol. 1,ed.E.R.Kandel (Baltimore: Williams \& Wilkins), 39-97.

Renshaw, B. (1941). Influence of discharge of motoneurons upon excitation of neighbouring motoneurons. J. Neurophysiol. 4, 167-183.

Renshaw, B. (1946). Central effects of centripetal impulses in axons of spinal ventral roots. J. Neurophysiol. 9 , 191-204.

Russier, M., Kopysova, I. L., Ankri, N. Ferrand, N., and Debanne, D. (2002). GABA and glycine co-release optimizes functional inhibition in rat brainstem motoneurons in vitro. $J$. Physiol. (Lond.) 541, 123-137.

Sarto-Jackson, I., and Sieghart, W (2008). Assembly of GABA(A) receptors (Review). Mol. Membr. Biol. 25, 302-310.

Simon,E.S. (1995). Involvement of glycine and GABAA receptors in the pathogenesis of spinal myoclonus: in vitro studies in the isolated neonatal rodent spinal cord. Neurology 45, 1883-1892.

Simon, E. S. (1997). Phenotypic heterogeneity and disease course in three murine strains with mutations in genes encoding for alpha 1 and beta glycine receptor subunits. Mov. Disord. 12, 221-228.

Strata, P., and Harvey, R. (1999). Dale's principle. Brain Res. Bull. 50, 349-350.
Stuart, D. G., and Pierce, P. A. (2006). The academic lineage of Sir John Carew Eccles (1903-1997). Prog. Neurobiol. 78, 136-155.

Stuart, G. J., and Redman, S. J. (1990). Voltage dependence of Ia reciprocal inhibitory currents in cat spinal motoneurones. J. Physiol. (Lond.) 420, 111-125.

Takahashi, T., and Momiyama, A. (1991). Single-channel currents underlying glycinergic inhibitory postsynaptic responses in spinal neurons. Neuron 7, 965-969.

Triller, A., Cluzeaud, F., Pfeiffer, F., Betz, H., and Korn, H. (1985). Distribution of glycine receptors at central synapses: an immunoelectron microscopy study. J. Cell Biol. 101, 683-688.

vonWegerer,J.,Becker,K.,Glockenhammer, D., Becker, C. M., Zeilhofer, H. U., and Swandulla, D. (2003). Spinal inhibitory synaptic transmission in the glycine receptor mouse mutant spastic. Neurosci. Lett. 345, 45-48.

Werman, R., Davidoff, R.A., and Aprison, M. H. (1967). Inhibition of motoneurones by iontophoresis of glycine. Nature 214, 681-683.

Werman, R., Davidoff, R.A., and Aprison, M.H. (1968). Inhibitory action of glycine on spinal neurons in the cat. $J$. Neurophysiol. 31, 81-95.

Windhorst, U. (1996). On the role of recurrent inhibitory feedback in motor control. Prog. Neurobiol. 49, 517-587.

Woodbury, J.W., and Patton, H. D. (1952). Electrical activity of single spinal cord elements. Cold Spring Harb. Symp. Quant. Biol. 17, 185-188.

Zeilhofer, H. U. (2005). The glycinergic control of spinal pain processing. Cell. Mol. Life Sci. 62, 2027-2035.

Conflict of Interest Statement: The authors declare that the research was conducted in the absence of any commercial or financial relationships that could be construed as a potential conflict of interest.

Received: 23 December 2009; paper pending published: 15 January 2010; accepted: 28 April 2010; published online: 21 May 2010

Citation: Callister RJ and Graham BA (2010) Early history of glycine receptor biology in mammalian spinal cord circuits. Front. Mol. Neurosci. 3:13. doi: 10.3389/ fnmol.2010.00013

Copyright (C) 2010 Callister and Graham. This is an open-access article subject to an exclusive license agreement between the authors and the Frontiers Research Foundation, which permits unrestricted use, distribution, and reproduction in any medium, provided the original authors and source are credited. 